\title{
Estimated Glomerular Filtration Rate and Serum Creatinine Level as Predictors of Global Cognition in Elderly with Chronic Kidney Disease and Normal Muscle Mass
}

Aya M. Sayed ${ }^{a}$, Ahmed M. Tawfik ${ }^{b}$, Mennatallah S. Al-Araby ${ }^{a}$, Hoda M. F. Wahba ${ }^{a}$, Manar M. Adel $^{a}$, Mohammed H. EL-Banouby ${ }^{a}$

${ }^{a}$ Geriatrics and Gerontology department, Faculty of Medicine, Ain Shams University.

${ }^{b}$ Internal Medicine and Nephrology department, Faculty of Medicine, Ain Shams University.

\begin{abstract}
Background: Chronic kidney disease (CKD) and cognitive impairment are important and prevalent public health problems that lead to increase the risk of morbidity and mortality. Both are considered a major social and financial burden.
\end{abstract}

Cognitive impairment commonly occurs in individuals with CKD; therefore cognitive assessment is extremely important. Early diagnosis and intervention help to decrease the progression of cognitive impairment.

Aim: To identify the relation between serum creatinine level and estimated glomerular filtration rate (e-GFR) and global cognitive function (Mini Mental State Examination (MMSE) score in Egyptian elderly with CKD stages 2-4 with normal muscle mass.

Methods: Cross-sectional study was conducted at the Geriatrics in-patient wards and outpatient clinics at Ain Shams University Hospitals, Cairo, Egypt, over six months. Fourty five elderly patients who had CKD stages 2-4 with normal muscle mass index were included in the study. Muscle mass was assessed using Bio Electrical Impedance analysis (BIA). History was taken from all participants followed by assessment of the global cognitive function by MMSE, measurement of the serum creatinine level and e-GFR by 24 hours urinary creatinine clearance.

Results: There was a significant negative correlation between serum creatinine level and MMSE Score, and a significant positive correlation between e-GFR and MMSE score. By regression analysis of possible confounding factors, only e-GFR not serum creatinine level shows a significant correlation with MMSE.

Conclusion: e-GFR not serum creatinine level is associated with a lower MMSE score in elderly despite having normal muscle mass.

Keywords: Chronic kidney disease, e-GFR, cognitive impairment, global cognition.

\section{Background}

CKD is a globally important public health problem, which leads to end-stage renal disease (ESRD) and increases the risk of morbidity and mortality . ${ }^{1}$

The prevalence of CKD in general populations is 11 $13 \%$ worlidwide. $^{2}$ In Egypt the highest percentage of patients with CKD (31.9\%) was found to be between 50 and 60 years. $^{3}$

Patients with CKD have a higher prevalence of cognitive dysfunction than the general population even when accounting for other risk factors such as age, diabetes, cardiovascular risk and other comorbidities. ${ }^{4}$ Cognitive impairment impacts patients negatively by contributing to functional dependence and behavioral symptoms that result in poor outcomes and decreased medication and medical care compliance. These negative consequences result in a downward spiral of functional decline and an accelerated loss of independence, which leads to premature 
institutionalization . ${ }^{5}$

Moreover, cognitive function has been found to be correlated with frailty and measures of depression. ${ }^{6}$ Additionally, it doubles the mortality risk and increases days spent in the hospital ${ }^{5}$, contributing to the social and economic burden of CKD.

The risk of cognitive impairment in patients with CKD is due to the high prevalence of ischemic, symptomatic or asymptomatic cerebrovascular injuries. ${ }^{7}$ This vascular mechanism may explain the association between risk factors affecting both the brain and the kidneys and their potential exacerbation in renal disease. $^{8}$

Oxidative stress, immune inflammatory processes, anemia, hyper-homocysteinemia, and vitamin B12 deficiency may be involved with this decline in neurocognitive performance. ${ }^{9}$

Cognitive assessment in individuals with CKD is important. Due to the complexity of CKD, patients have to process and understand significant amounts of information in order to properly comply with the treatment. Early diagnosis and intervention help contain or decrease the progress of cognitive impairment. ${ }^{10}$

During the last decades, in clinical practice and in most studies, serum creatinine concentration has become the most commonly used marker to estimate GFR ${ }^{11}$. Creatinine is derived largely from skeletal muscle, which limits the ability of creatinine to assess kidney function accurately among persons with different levels of muscle mass in elderly population. ${ }^{12}$

The current work's aim was to study the association between serum creatinine and e-GFR, as markers of renal function, and the MMSE score, as a test of global cognitive function, in the Egyptian elderly who had CKD stages 2-4 with normal muscle mass index.

\section{Methods}

Observational cross-sectional study conducted at the Geriatrics department inpatient wards and outpatient clinics at Ain Shams University Hospitals, Cairo, Egypt.

Forty five Participants were recruited from January 2018 till the sample was completed over 6 months.

Inclusion criteria were: participants 60 years and older who had CKD stages 2-4 with normal muscle mass index.

Stages of CKD as defined by Kidney disease improving global outcomes (KDIGO) guidelines ${ }^{13}$ : Stage 2: GFR 60-89 $\mathrm{ml} / \mathrm{min} / 1.73 \mathrm{~m}^{2}$, Stage 3: 30-59 ml/min $/ 1.73 \mathrm{~m}^{2}$, Stage 4: GFR 15-29 ml/min/1.73 $\mathrm{m}^{2}$. Assessment of muscle mass index by using Bio Electrical Impedance Analysis (BIA): EWGSOP (European Working Group on Sarcopenia in Older People) defined the cut off points of skeletal muscle mass index. ${ }^{14}$ In men: normal muscle mass index $\geq 10.76 \mathrm{~kg} / \mathrm{m}^{2}$ and in women: normal muscle mass index $\geq 6.76 \mathrm{~kg} / \mathrm{m}^{2}$.

Participants who refused to participate, had stage 1 and $5 \mathrm{CKD}$, patients was on renal replacement therapy and who had a low muscle mass index were excluded.
Acceptance of ethical committee of faculty of medicine, Ain shams university, was taken. Informed oral consent was taken from all subjects, sociodemographic data, a detailed medical history and clinical examination was done.

Assessment of global cognitive function by Mini Mental State Examination (MMSE) ${ }^{15}$ using the Arabic version 16 .

Venous blood sample not necessary fasting, to measure serum creatinine level.

Estimation of GFR by 24 hours urinary creatinine clearance: subjects were told to collect 24 hour urine and e-GFR was calculated by multiplying the ratio of urine creatinine $(\mathrm{Cr})$ to plasma $\mathrm{Cr}$.

\section{Statistical Methods}

Data were collected, revised, coded and entered to the Statistical Package for Social Science (IBM SPSS) version 23. The quantitative data were presented as mean, standard deviations and ranges when parametric. Also, qualitative variables were presented as number and percentages.

Logistic regression models were used to find out independent factors affecting certain conditions.

\section{Results}

In this cross-sectional study that recruited 45 elderly with CKD stages 2-4 with normal muscle mass index, the mean age was $68 \pm 2.1$ years; most of them were males, obese, non-smokers (table1a \&1b).

The sample included patients in stage 2-4 CKD, stage $2,12(26.7 \%)$ subjects, stage 3, $24(53.3 \%)$ and stage 4 , $9(20 \%)$ subjects.

The mean serum creatinine of the participants was 1.48 \pm 0.54 and the mean of the e-GFR was $47.68 \pm 18.32$ $\mathrm{ml} / \mathrm{min} / 1.73 \mathrm{~m}^{2}$ (table 2).

The mean of MMSE score was $26.87 \pm 1.95$. Elderly with an advanced stage of CKD had a lower MMSE score; in the elderly with the stage $2 \mathrm{CKD}$, the MMSE score mean was $28 \pm 1.1$, while in stage $3 \mathrm{CKD}$ the mean was $27.04 \pm 1.4$ and the mean of MMSE score in stage 4 was $24.3 \pm 1$.

The current study shows that both serum creatinine and e-GFR as markers of kidney function have a significant correlation with MMSE score as a marker of global cognitive function, indicating that the poorer kidney functions the lower MMSE score. These correlations were negative correlation between the serum creatinine level and MMSE score, and a positive correlation between e-GFR and MMSE score. Also, there was a significant negative correlation between the number of comorbidities and MMSE score, the elderly with a higher number of comorbidities showed a lower MMSE score (table 3 ).

After regression analysis of all studied coefficient factors (serum creatinine level, e-GFR and number of comorbidities), only e-GFR was significantly associated with MMSE score not serum creatinine despite normal muscle mass which is the direct factor which affect serum creatinine level (table 4). 
Sayed AM et al., EJGG.2020; 7(1):42-47

Table 1: The descriptive data of the studied population:

Table 1a:

\begin{tabular}{lcc}
\hline & No. (45) & \\
Sex & & \\
$\quad$ Female & 18 & $40 \%$ \\
$\quad$ Male & 27 & $60 \%$ \\
Education & & \\
$\quad$ Illiterate & 24 & $53.3 \%$ \\
$\quad$ Educated & 21 & $46.7 \%$ \\
Marital status & 1 & $2.2 \%$ \\
Single & 17 & $37.8 \%$ \\
$\quad$ Widowed & 26 & $57.8 \%$ \\
Married & 1 & $2.2 \%$ \\
Divorced & & \\
Smoking & & $48.9 \%$ \\
$\quad$ No & 22 & $28.9 \%$ \\
Yes & 13 & $22.2 \%$ \\
Ex & 10 & \\
Number of comorbidities & & $\mathbf{1 7 . 7 \%}$ \\
$\mathbf{1 - 2}$ & 8 & $\mathbf{4 8 . 8 \%}$ \\
$\mathbf{3 - 5}$ & 22 & \\
\hline 5 & 15 & \\
\hline
\end{tabular}

Table 1b:

\begin{tabular}{lc} 
Age & $68 \pm 2.1$ \\
Mean \pm SD & $60-89$ \\
Range & \\
& \\
Weight $($ Kg) & \\
Mean \pm SD & $82.72 \pm 10.27$ \\
Range & $63-103$ \\
Height $(\mathrm{cm})$ & \\
Mean \pm SD & $166.08 \pm 5.26$ \\
Range & $153-176$ \\
Body Mass Index $(\mathrm{BMI})(\mathrm{Kg} / \mathrm{m} 2)$ & \\
Mean \pm SD & $29.78 \pm 3.46$ \\
Range & $21.5-36.5$ \\
\hline
\end{tabular}

Table (2): Serum creatinine level and the e-GFR of the studied population:

\begin{tabular}{lc}
\hline Serum creatinine $(\mathrm{mg} / \mathrm{dl})$ & \\
Mean \pm SD & $1.48 \pm 0.54$ \\
& $0.8-3.4$ \\
Range & \\
e-GFR by urine creatinine clearance $(\mathrm{ml} / \mathrm{min} / 1.73 \mathrm{~m} 2)$ & $47.68 \pm 18.32$ \\
Mean \pm SD & $16-80$ \\
Range & \\
& \\
\hline
\end{tabular}


Table (3): The correlations with MMSE score:

\begin{tabular}{lcc}
\hline & $\mathbf{r}$ & p value \\
Age & 0.122 & 0.426 \\
Body mass index & -0.177 & 0.244 \\
e-GFR by urine creatinine clearance & 0.638 & $<\mathbf{0 . 0 0 1} *$ \\
Serum creatinine & & $\mathbf{0 . 0 0 2 *}$ \\
Number of comorbidities & -0.446 & $\mathbf{0 . 0 0 9 *}$ \\
\hline
\end{tabular}

Table (4) Regression analysis of the coefficients factors:

\begin{tabular}{llllll}
\hline & \multicolumn{2}{l}{$\begin{array}{l}\text { Unstandardized } \\
\text { Coefficients }\end{array}$} & $\begin{array}{l}\text { Standardized } \\
\text { Coefficients }\end{array}$ & t & P- \\
& B & Std. Error & Beta & value \\
& 0.045 & 0.022 & 0.428 & 2.060 & $\mathbf{0 . 0 4 6 *}$ \\
$\begin{array}{l}\text { e-GFR by urine } \\
\text { creatinine clearance }\end{array}$ & 0.096 & 0.655 & 0.027 & 0.146 & 0.884 \\
$\begin{array}{l}\text { Serum Creatinine } \\
\begin{array}{l}\text { Number of } \\
\text { commodities }\end{array}\end{array}$ & -0.209 & 0.183 & -0.290 & -1.145 & 0.259 \\
\hline
\end{tabular}

\section{Discussion:}

In this observational cross-sectional study that recruited 45 elderly with CKD stages 2-4 with normal muscle mass index, the mean age was $68 \pm 2.1$ years; most of them were males, obese, non-smokers.

This study shows that even in patients with normal muscle mass, e-GFR and not serum creatinine is a reliable predictor for MMSE scores.

Serum creatinine level has been for years, the most convenient measure for deteriorating kidney functions. Yet, all recent studies question its accuracy and early prediction ability especially in elderly. This is mainly due to its false low levels in elderly with low muscle mass that naturally occurs with age. This has made it crucial to search for more accurate and early predictors. The shift has not been limited to finding early predictors of kidney functions but also to detecting early correlated co-morbidities that unfortunately worsen the prognosis and quality of life of these patients and their families. One of the most important and debilitating of these co-morbidities is the decline in cognitive functions.

There is agreement by most of the studies that cognitive changes occur early in CKD, and that these changes progress at different rates for different cognitive domains as CKD progresses and e-GFR declines. ${ }^{17,18,19}$ Some studies worked on global cognitive function, as Tamura et al., ${ }^{20}$ in a cross-sectional study revealing that in patients with CKD, each $10-\mathrm{mL} / \mathrm{min} / 1.73 \mathrm{~m}^{2}$ decrease in e-GFR less than $60 \mathrm{~mL} / \mathrm{min} / 1.73 \mathrm{~m}^{2}$ was associated with an $11 \%$ increased prevalence of cognitive impairment. Similarly, Sasaki and colleagues 21 found that CKD was strongly associated with the incidence of dementia independent of other confounders.

Others worked on specific cognitive domains as Berger and colleagues $^{22}$ who found that CKD patients performed worse than control groups on orientation \& attention, language, concept formation \& reasoning, memory, executive function, and global cognition tests. The early effect of CKD was mainly on orientation \& 
attention.

Yaffe et al., ${ }^{5}$ confirmed this by applying a battery of six neuropsychological tests (the Modified Mini-Mental State Examination (3MS), the Trail Making Test Parts A and B (Trails A and B), Category (verbal) Fluency, Buschke Selective Reminding Test (immediate and delayed memory), and Boston Naming). They reported a positive relation between e-GFR and global cognitive function that was observed for most cognitive domains, patients with e-GFR $<30 \mathrm{ml} / \mathrm{min}$ per $1.73 \mathrm{~m}^{2}$ were more likely to have cognitive impairment as revealed by tests evaluating global cognition, naming, attention, executive function, and delayed memory, but not tests assessing fluency and immediate memory.

Other epidemiological studies worked on the hypothesis of the cognitive impairment in the stable CKD patients, Khatri and colleagues ${ }^{23}$ in a study that included 615 stroke-free community residents, found that CKD is associated with white matter hyperintensity volume, suggesting the hypothesis that CKD is associated with inflammation and endothelial dysfunction, causing pathogenesis of white matter hyper-intensity, which was a risk for stroke and dementia, CKD was found to be a possible determinant for cerebrovascular disease and micro-angiopathy.

Regarding the studies concerning which renal function test is a best predictor of cognitive impairment, there were controversial results about kidney function tests association with cognitive function. These controversial results may be due to different population characteristics and different methods of assessment. Our study results agree with Tamura et al., ${ }^{24}$ who found that a lower GFR was associated with poorer cognitive function by MMSE score, independent of traditional vascular risk factors. Moreover, they also found that serum creatinine showed no correlation with MMSE score.

Similarly, Kurella and colleagues ${ }^{25}$ in a crosssectional study included 80 subjects with CKD Stages 3 and 4 not requiring dialysis and 80 subjects with CKD Stage $\mathrm{V}$ on hemodialysis (ESRD) found that the severity of kidney disease by GFR but in contrast to our study serum creatinine level was directly related to the severity of cognitive impairment even after adjustment of other confounding factors.

Also, Shi et al., ${ }^{26}$ found that the Montreal Cognitive Assessment (MOCA) scores were positively correlated with GFR ( $\mathrm{r}=0.379, \mathrm{P}<0.05)$.

Martens and colleagues ${ }^{27}$ in a study of the associations of GFR and cognitive function found that they were strongly positively associated. Also, Romijn et al., ${ }^{28}$ found that there is a significant association between mild CKD by GFR and serum creatinine and impaired cognitive function.

On the other hand, Joosten et al., ${ }^{29}$ showed that there was no association of the e-GFR or serum creatinine with cognitive function. This difference may be due to that Joosten's study included a younger age group (2875 years), not only geriatric participants. The same was found by Helmer and colleagues ${ }^{30}$ who revealed that there was no increased risk of cognitive decline or dementia associated with low e-GFR level. This difference may be due to a different method of estimating GFR and only $12 \%$ of the participants in Helmer's study had GFR $<60 \%$.

From the result of the current study we believe that, the cognitive function in the elderly with CKD must be one of the physician's priorities, depending on e-GFR not only serum creatinine level even in early stages of CKD.

Although e-GFR is not as readily available as serum creatinine but its prediction capacity for cognitive function in patients with CKD stages 2-4 with normal muscle mass is worth the effort and money. Nevertheless, it is important to put in mind that many factors interplay when laying down the conclusion of the study. It is also important to put into consideration that the MMSE score is only an indication of global cognitive functions; different domains have not been separately assessed.

Conclusion: Lower e-GFR is an independent factor correlated positively to MMSE score even in stage 2-4 of CKD, but serum creatinine after regression analysis didn't show such correlation in elderly with CKD stage 2-4 with normal muscle mass

\section{References}

[1] Astor BC, Matsushita K, Gansevoort RT, Van Der Velde M, Woodward M, Levey AS, De Jong PE, Coresh J, Chronic Kidney Disease Prognosis Consortium. Lower estimated glomerular filtration rate and higher albuminuria are associated with mortality and end-stage renal disease. $A$ collaborative meta-analysis of kidney disease population cohorts. Kidney international. 2011 Jun 2;79(12):1331-40.

[2] Hill NR, Fatoba ST, Oke JL, Hirst JA, O'Callaghan CA, Lasserson DS, Hobbs FR. Global prevalence of chronic kidney disease-a systematic review and meta-analysis. PloS one. $2016 \mathrm{Jul}$ 6; 11(7):e0158765.

[3] Ghonemy TA, Farag SE, Soliman SA, El-Okely A, El-Hendy Y. Epidemiology and risk factors of chronic kidney disease in the El-Sharkia Governorate, Egypt. Saudi Journal of Kidney Diseases and Transplantation. 2016 Jan 1;27(1):111.

[4] Yaffe K, Ackerson L, Tamura MK, Le Blanc P, Kusek JW, Sehgal AR, Cohen D, Anderson C, Appel L, DeSalvo K, Ojo A. Chronic kidney disease and cognitive function in older adults: findings from the chronic renal insufficiency cohort cognitive study. Journal of the American Geriatrics Society. 2010 Feb; 58(2):338-45.

[5] Weiner DE, Seliger SL. Cognitive and physical function in chronic kidney disease. Current opinion in nephrology and hypertension. 2014 May;23(3):291.

[6] McAdams-DeMarco MA, Tan J, Salter ML, Gross A, Meoni LA, Jaar BG, Kao WH, Parekh RS, Segev DL, Sozio SM. Frailty and cognitive function in incident hemodialysis patients. Clinical Journal of the American Society of Nephrology. 2015 Dec 7;10(12):2181-9.

[7] McQuillan R, Jassal SV. Neuropsychiatric complications of chronic kidney disease. Nature Reviews Nephrology. 2010 Aug;6(8):471..

[8] Helmer C, Stengel B, Metzger M, Froissart M, Massy ZA, Tzourio C, Berr $C$, Dartigues JF. Chronic kidney disease, cognitive decline, and incident dementia: the 3C Study. Neurology. 2011 Dec 6;77(23):2043-51.

[9] Small DM, Coombes JS, Bennett N, Johnson DW, Gobe GC. Oxidative stress, anti-oxidant therapies and chronic kidney disease. Nephrology. 2012 May;17(4):311-21.

[10] Silva STD, Ribeiro RD L, Rosa CDOB, Cotta RMM. Capacidade cognitiva de indivíduos com doença renal crônica: relação com características demográficas e clínicas. Brazilian Journal of Nephrology, 2014, 36(2), 163-170. 
[11] Hojs R, Bevc S, Ekart R, Gorenjak M, Puklavec L.Serum cystatin C as an endogenous marker of renal function in patients with mild to moderate impairment of kidney function. Nephrology Dialysis Transplantation. 2006;21(7):1855-1862.

[12] Froissart M, Rossert J, Jacquot C, Paillard M, Houillier P. Predictive performance of the modification of diet in renal disease and CockcroftGault equations for estimating renal function. J Am Soc Nephrol 2005; 16 : 763-773.

[13] Kidney Disease Improving Global Outcomes (KDIGO) CKD Work Group: KDIGO 2012 clinical practice guideline for the evaluation and management of chronic kidney disease kidney Int Suppl, 3 (2013), pp. 1. 150.

[14] Cruz-Jentoft AJ, Baeyens JP, Bauer JM, Boirie Y, Cederholm T, Landi F, Martin FC, Michel JP, Rolland Y, Schneider SM, Topinková E. Sarcopenia: European consensus on definition and diagnosisReport of the European Working Group on Sarcopenia in Older PeopleA. J. Cruz-Gentoft et al. Age and ageing. $2010 \mathrm{Jul}$ 1;39(4):412-23.

[15] Folstein MF, Folstein SE, McHugh PR. "Mini-mental state": a practical method for grading the cognitive state of patients for the clinician. Journal of psychiatric research. 1975 Nov 1; 12(3):189-98.

[16] El-OkI MA, El Banouby MH, El Etrebi A. Prevalence of Alzheimer dementia and other causes of dementia in Egyptian elderly. MD thesis, Faculty of Medicine, Ain Shams University. 2002.

[17] Hailpern SM, Melamed ML, Cohen HW, Hostetter TH. Moderate chronic kidney disease and cognitive function in adults 20 to 59 years of age: Third National Health and Nutrition Examination Survey (NHANES III). Journal of the American Society of Nephrology. $2007 \mathrm{Jul}$ 1;18(7):2205-13. [18] Elias MF, Elias PK, Seliger SL, Narsipur SS, Dore GA, Robbins MA. Chronic kidney disease, creatinine and cognitive functioning. Nephrology Dialysis Transplantation. 2009 Mar 18;24(8):2446-52.

[19] Yang A, Tsai SJ, Yeh HL, Chen JY, Liou YJ, Hwang JP, Hong CJ. Association between renal function and cognitive performance in elderly community-dwelling men without dementia. Journal of the American Geriatrics Society. 2010 Oct 1;58(10):2046-8.

[20] Tamura MK, Wadley V, Yaffe K, McClure LA, Howard G, Go R, Allman RM, Warnock DG, McClellan W. Kidney function and cognitive impairment in US adults: the Reasons for Geographic and Racial Differences in Stroke (REGARDS) Study. American Journal of Kidney Diseases. 2008 Aug $1 ; 52(2): 227-34$.
[21] Sasaki Y, Marioni R, Kasai M, Ishii H, Yamaguchi S, Meguro K. Chronic kidney disease: a risk factor for dementia onset: a population-based study. The Osaki-Tajiri Project. Journal of the American Geriatrics Society. 2011 Jul;59(7):1175-81.

[22] Berger I, Wu S, Masson P, Kelly PJ, Duthie FA, WhiteleyW,\& Webster AC. Cognition in chronic kidney disease: a systematic review and metaanalysis. BMC medicine, 2016, 14(1), 206.

[23] Khatri M, Wright CB, Nickolas TL, Yoshita M, Paik MC, Kranwinkel G, Sacco RL, DeCarli C. Chronic kidney disease is associated with white matter hyperintensity volume: the Northern Manhattan Study (NOMAS). Stroke. 2007 Dec 1;38(12):3121-6.

[24] Tamura MK, Xie D, Yaffe K, Cohen DL, Teal V, Kasner SE, Messé SR, Sehgal AR, Kusek J, DeSalvo KB, Cornish-Zirker D. Vascular risk factors and cognitive impairment in chronic kidney disease: the Chronic Renal Insufficiency Cohort (CRIC) study. Clinical journal of the American Society of Nephrology. 2011 Feb 1;6(2):248-56.

[25] Kurella M, Yaffe K, Shlipak MG, Wenger NK, Chertow GM. Chronic kidney disease and cognitive impairment in menopausal women. American Journal of Kidney Diseases. 2005 Jan 1; 45(1):66-76.

[26] Shi X, Zhang Y, Niu H, Wang R, Shen J, Zhou S, Yang H, Wang S, Wu J. Correlation between cognitive impairment and diabetic nephropathy in patients with Type 2 diabetes mellitus. Zhong nan da xue xue bao. Yi xue ban= Journal of Central South University. Medical sciences. 2016 Feb; 41(2):143-50.

[27] Martens RJ, Kooman JP, Stehouwer CD, Dagnelie PC, van der Kallen CJ, Koster A, Kroon AA, Leunissen KM, Nijpels G, van der Sande FM, Schaper NC. Estimated GFR, albuminuria, and cognitive performance: the Maastricht Study. American Journal of Kidney Diseases. 2017 Feb 1; 69(2):179-91.

[28] Romijn MD, Van Marum RJ, Emmelot-Vonk MH, Verhaar HJ, Koek HL. Mild chronic kidney disease is associated with cognitive function in patients presenting at a memory clinic. International journal of geriatric psychiatry. $2015 \mathrm{Jul} ; 30(7): 758-65$.

[29] Joosten $H$, Izaks GJ, Slaets JP, de Jong PE, Visser ST, Bilo HJ, Gansevoort RT. Association of cognitive function with albuminuria and eGFR in the general population. Clinical Journal of the American Society of Nephrology. 2011 Jun 1;6(6):1400-9.

[30] Helmer C, Stengel B, Metzger M, Froissart M, Massy ZA, Tzourio C Berr C, Dartigues JF. Chronic kidney disease, cognitive decline, and incident dementia: the 3C Study. Neurology. 2011 Dec 6;77(23):2043-51. 